\title{
Percutaneous left stellate ganglion block in patients with electrical storm. Our preliminary results.
}

Simone Savastano, MD; Enrico Baldi, MD; Veronica Dusi,MD; Antonio Sanzo,MD; Rita Camporotondo, MD; Roberto Rordorf, MD; Alessandro Vicentini, MD; Barbara Petracci, MD; Luigi Oltrona Visconti, MD; Gaetano Maria De Ferrari,MD.

Purpose The treatment of electrical storm (ES) is a major challenge as conventional drugs are often ineffective. There are limited evidences about the use of percutaneous left stellate ganglion block (PSGB) in this setting, so we sought to assess its feasibility and effectiveness in the case of in-hospital refractory ES.

Methods. We enrolled all the consecutive drug refractory ES occurred at the IRCCS Policlinico San Matteo in Pavia between November and December 2017. PSGB has been provided by the echo-guided injection of $10 \mathrm{ml}$ of local anesthetic (lidocaine $200 \mathrm{mg}$ or bupivacaine $50 \mathrm{mg}$ ) at the level of transverse process of $\mathrm{C} 6$.

Results. PSGB has been provided in three patients: a 47 years old male (pt 1) with ventricular arrhythmias due to a right ventricular arrhythmogenic dysplasia; a 89 years old female (pt 2) with a myocardial infarction complicated by refractory ventricular fibrillation (VF) and a 78 years old female (pt 3) for recurrent episodes of VF three day after an acute myocardial infarction. Pt 1 and 3 were conscious at the moment of the procedure and they received $50 \mathrm{mg}$ of bupivacaine (after 7 and 4 arrhythmic relapses respectively). Pt 3 underwent to the PSGB with $200 \mathrm{mg}$ of lidocaine during resuscitation for refractory VF after 7 ineffective shocks. In all the three patients after the PSGB there was an arrhythmias free interval of 4 hours, fifteen minutes and 72 hours respectively. No complications occurred.

Conclusions. Our preliminary results, even if on a limited population, suggest the feasibility and the effectiveness of the PSGB for patients with life-threatening ventricular arrhythmias.

RESUSCITATION 2018 New technologies in resuscitation 20-21-22 September $\bullet$ Bologna • Italy
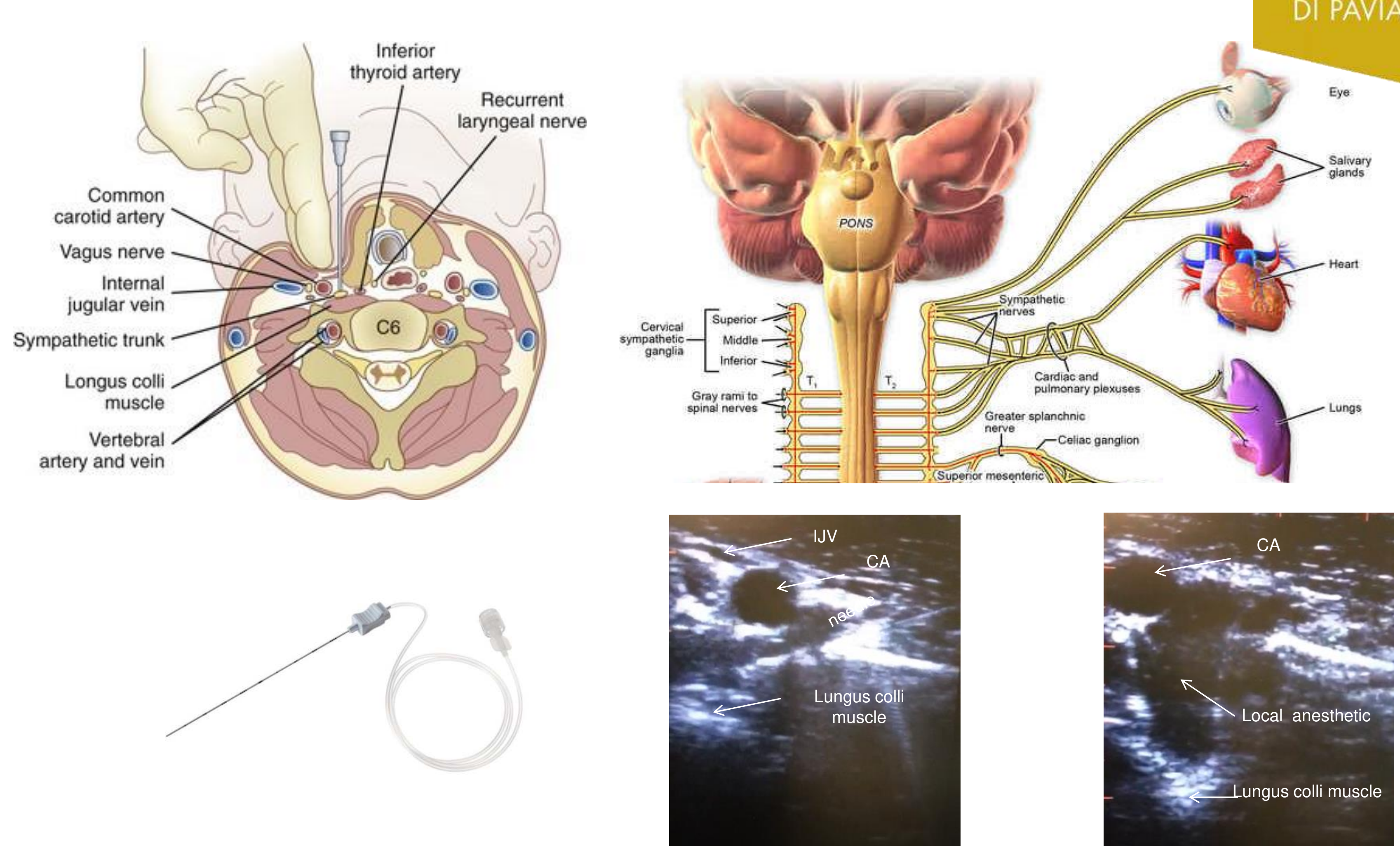

\begin{tabular}{|r|r|r|r|r|r|}
\hline Case & Diagnosis & Arrhythmias & Anesthetic & $\begin{array}{r}\text { DC-Shock } \\
\text { before } \\
\text { PSGB }\end{array}$ & $\begin{array}{r}\text { Free } \\
\text { interval }\end{array}$ \\
\hline$\# 1$ & ARVD & VT & Bupivacaine & 7 & $4 \mathrm{~h}$ \\
\hline$\# 2$ & AMI & VF & Lidocaine & 7 & $15 \mathrm{~min}$ \\
\hline$\# 3$ & AMI & VF & Bupivacaine & 4 & $72 \mathrm{~h}$ \\
\hline$\# 4$ & $\begin{array}{r}\text { Cardiogeni } \\
\text { c shock }\end{array}$ & VT & Bupivacaine & 9 & $6 \mathrm{~h}$ \\
\hline & & & & \\
\hline
\end{tabular}

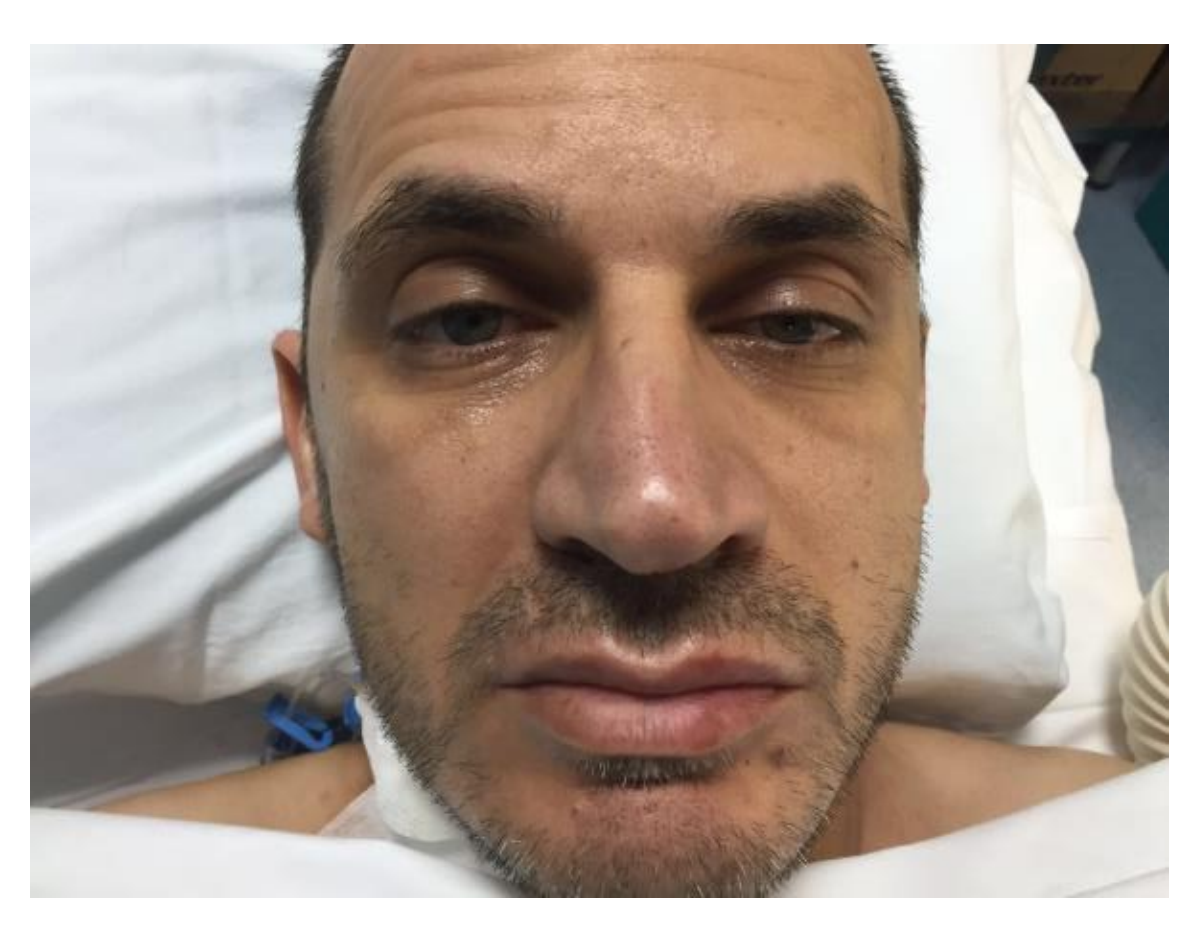

